\title{
An experimental study of thermocapillary rupture of a locally heated horizontal liquid layer on various substrates
}

\author{
Dmitry Kochkin ${ }^{1,2, *}$ \\ ${ }^{1}$ Kutateladze Institute of Thermophysics, 630090 Novosibirsk, Russia \\ ${ }^{2}$ Novosibirsk State Technical University, 630073 Novosibirsk, Russia
}

\begin{abstract}
This article experimentally studies a thermocapillary rupture of a locally heated horizontal liquid film on substrates of different materials and different thickness. In the course of work the dependence of the critical heat flux on the initial and final film thickness was determined. Upon reaching the heat flux and film thickness at which the liquid film boils up, the film disrupts at almost constant finite thickness. The research has shown that with an increase in thermal conductivity and thickness of the substrate the critical heat flux increases. On the substrates of a material with high thermal conductivity (copper) the heat flux is redistributed on the substrate; at that the localization of heating is lost, and the rupture is not observed.
\end{abstract}

\section{Introduction}

The devices using liquid film flows are widely used in industry. Thin liquid films are promising for cooling equipment with high local heat generation, in particular, highperformance electronics [1-3]. Such equipment requires removal of high local heat fluxes from electronic components such as computer chips and power electronics (transistors and thyristors).

The film cooling systems are efficient since they provide high intensity of heat and mass transfer at relatively low coolant flow rates. The decrease in film thickness allows enhancing heat and mass transfer; however, thin films are susceptible to ruptures, which leads to a drastic increase in the temperature of the cooled section and its failure.

Thermocapillary rupture of flowing liquid films under local heating were studied in [46]. Influence of substrate wettability and liquid properties on thermocapillary rupture of flowing films was studied in [7-9]. The paper [10] investigated the influence of substrate structuring on the rupture of flowing liquid films. Authors of $[11,12]$ were first to study the thermocapillary rupture of a stationary horizontal layer of fluid. The works [7, 13] showed that the critical heat flux for horizontal liquid films may several times exceed the heat flux for the films flowing under the action of gravity. This explains the motivation of our work.

*Corresponding author: kochkin1995@mail.ru 
The main goal of this research is to determine the dependence of the critical heat flux on the thickness of the horizontal liquid film using substrates of different materials and different thicknesses.

\section{Methods}

The experiments were conducted on locally heated substrates of copper, brass, stainless steel and glass with a diameter of $50.8 \mathrm{~mm}$ and thickness of 1 and $3 \mathrm{~mm}$. The substrate was mounted on a textolite base with a round copper rod with a diameter of $12.7 \mathrm{~mm}$ (Fig. 1). A ceramic heater was attached to the bottom of the rod. Heat flux was determined on electric power, dissipated on the ceramic heater. The working fluid was distilled water with an initial temperature of $25^{\circ} \mathrm{C}$. The liquid was supplied to the substrate by using a syringe pump. The substrate was cooled at the perimeter of the substrate. The water temperature in the cooling circuit was $10^{\circ} \mathrm{C}$.

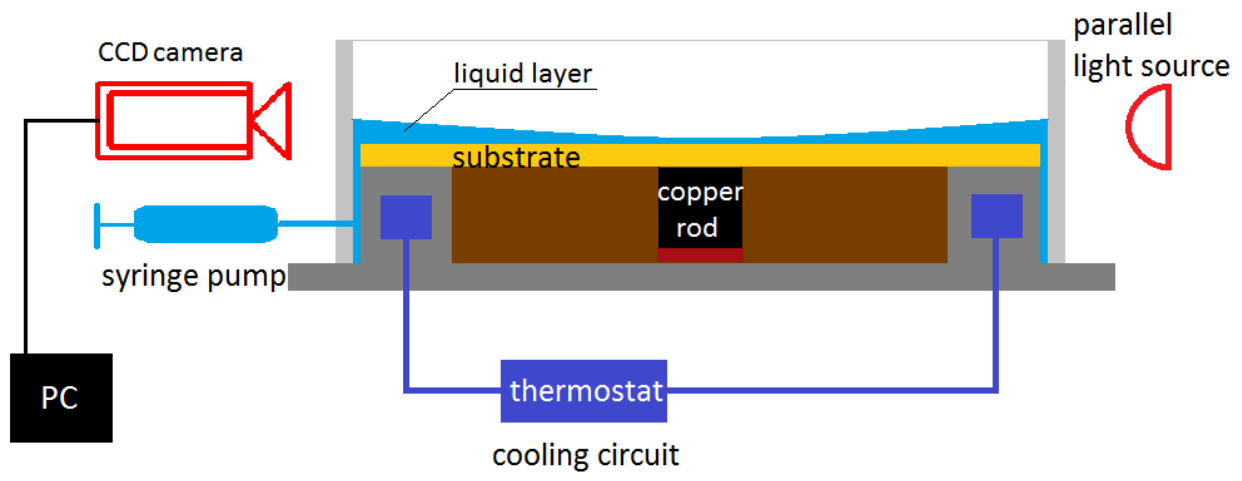

Fig. 1. Schematic diagram of the stand (the power source of the heater is not specified).

The use of replaceable substrates in this work allows studying the rupture of a horizontal liquid layer at different thermal conductivity and wettability of the substrate. To change wettability the substrate may be applied with various coatings that do not affect its thermal conductivity. In this work, coatings were not applied to the substrate.

To determine the layer thickness the optical method using a CCD camera DMK 23GP031 and source of parallel light MI-150 was applied (Fig. 2). This method caused a problem in determining the true liquid layer because of the meniscus preventing the observation. This was surmounted by mounting the parallel light source on the other side of the work section on the same axis with the camera. The light was reflected from the meniscus and did not enter the camera lens; however through the liquid layer the light freely penetrated, resulting in the light-struck band on the screen, being the image of the film thickness. Having obtained the film of the desired thickness, we gradually increased the heater power. When the film was disrupted, we fixed the critical heat flux (at the rupture) and the final (before rupture) thickness of the liquid layer. 


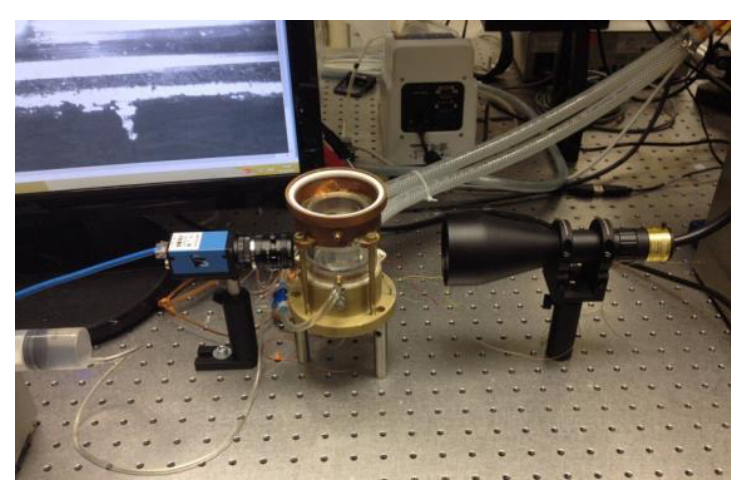

(a)

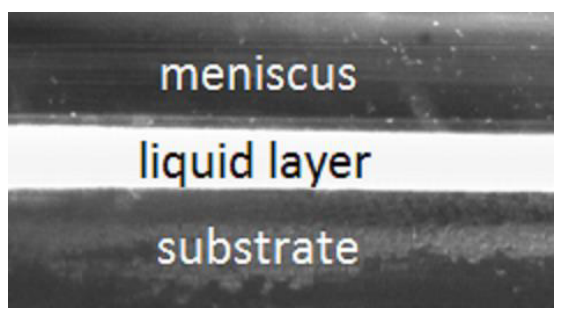

(b)

Fig. 2. Photo of experimental stand (a) and liquid layer $(b)$.

\section{Results}

According to the results of the experiments conducted on the glass substrate of $3 \mathrm{~mm}$ thickness, the graph of dependences of the critical heat flux (at film rupture) on the initial and final (before rupture) thicknesses of the fluid layer was built (Fig. 3). From its analysis it may be inferred that the larger the heat flux, the more intense liquid evaporation (the difference between the initial and final film thicknesses increases). Upon reaching the initial thickness $\sim 660 \mu \mathrm{m}$ and higher, the liquid starts boiling, until the film thickness becomes critical and the film disrupts; at that the value of finite thickness practically does not change. At small film thicknesses of 300-400 microns the final film thickness slightly decreases, as the evaporation is insignificant, and the graphs in this section are practically the same. When the thickness is up to $\sim 300 \mu \mathrm{m}$ the film disrupts without turning on the heater, which is apparently due to the fact that the air temperature is $15^{\circ} \mathrm{C}$ higher than the temperature of water in a cooling loop; hereupon the thermocapillary thinning of the film takes place.

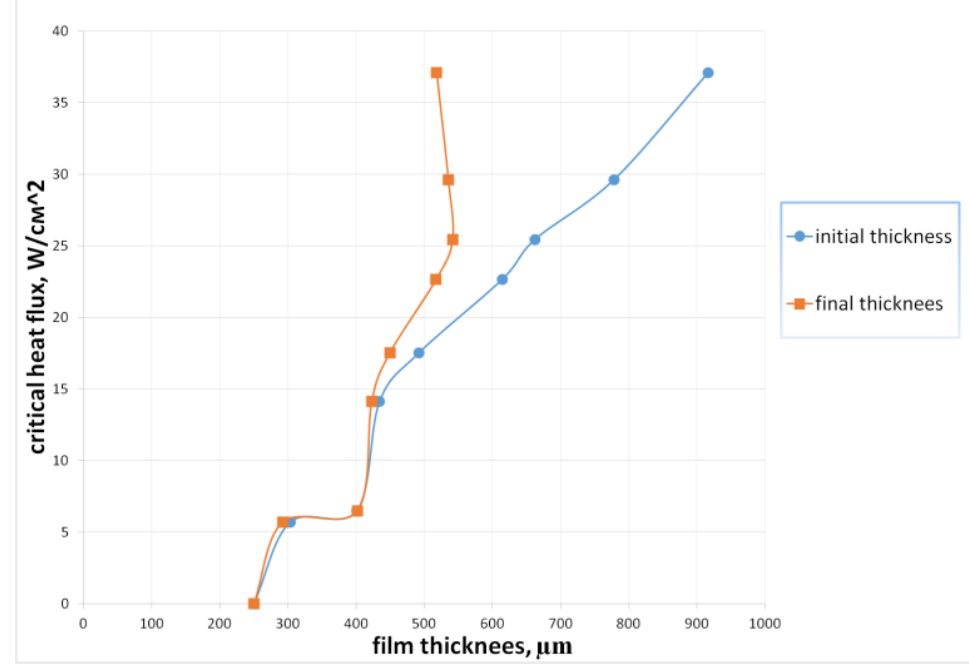

Fig. 3. Dependence of the critical heat flux on film thickness.

Figure 4 shows the dependence of the critical heat flux on the initial thickness of liquid film on stainless steel substrates of 1 and $3 \mathrm{~mm}$ thickness, and glass one with a thickness of 
$3 \mathrm{~mm}$. It is seen that on stainless steel substrates of $1 \mathrm{~mm}$ thickness the critical heat flux is several times lower than on substrates of the same material with a thickness of $3 \mathrm{~mm}$. This allows concluding that with increasing thickness of the substrate its heat resistance increases, hereupon the surface temperature of the substrate decreases. Apparently because of an increase in heat spreading in the substrate, the local heat flux density decreases. Because of the influence of these two factors the critical heat flux increases. From the comparison of dependencies for $3 \mathrm{~mm}$ thick stainless steel and glass substrates it is seen that the critical heat flux on the substrate of stainless steel is several times larger than on the glass one. It is apparently due to the fact that the thermal conductivity of stainless steel is 20 times higher than the one of glass that causes much larger spread of heat flux in the substrate. This decreases the locality of heating, and the critical heat flux increases.

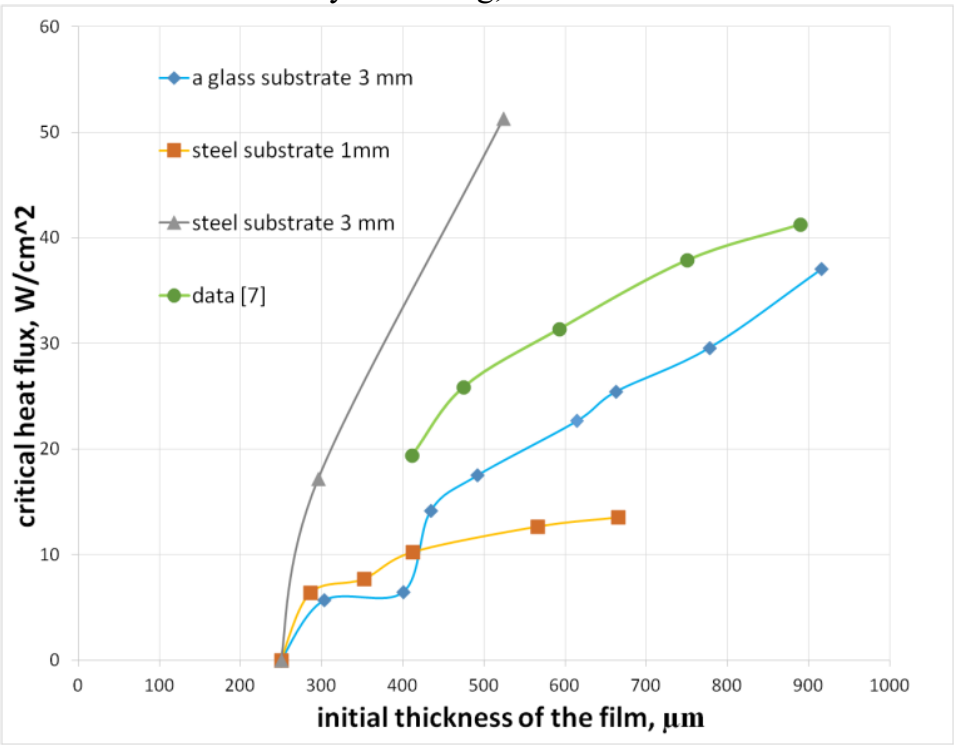

Fig. 4. Dependence of the critical heat flux on the initial film thickness.

\section{Conclusion}

It is established that with an increase in thermal conductivity and thickness of the substrate the critical heat flux for film rupture increases. When using substrates made of materials with high thermal conductivity (copper and brass) the heat flux is redistributed over the substrate and heat is removed to the cooling circuit; at that the film rupture is not observed. It is also worth noting that the final film thickness before rupture in the boiling liquid does not change.

The work was supported by the RF Ministry of Education and Science (Agreement No 14.604.21.0053, project identifier RFMEFI60414X0053).

\section{References}

1. D.V. Zaitsev, D.A. Rodionov, O.A. Kabov, Tech. Phys. Lett.+ 35, 680 (2009)

2. O.A. Kabov, D.V. Zaitsev, Multiphase Science and Technology 21, 249 (2009)

3. E.A. Chinnov, F.V. Ron'shin, O. A. Kabov, Interfacial Phenomena and Heat Transfer 3, 243 (2015) 
4. O.A. Kabov, Thermophys. Aerodyn. 7, 513 (2000)

5. E.A. Chinnov, O.A. Kabov, A.V. Muzykantov, D.V. Zaitsev, International Journal of Heat and Technology 19, 31 (2001)

6. D.V. Zaitsev, D.A. Rodionov, O.A. Kabov, Microgravity Sci. Technol. 19, 100 (2007)

7. D.V. Zaitsev, D.P. Kirichenko, and O.A. Kabov, Tech. Phys. Lett.+ 41, 551 (2015)

8. D.V. Zaitsev, A.A. Semenov, O.A. Kabov, Thermophys. Aeromech. 23, 625 (2016)

9. D.V. Zaitsev, O.A. Kabov, V.V. Cheverda, N.S. Bufetov, High Temp. 42, 450 (2004)

10. D.V. Zaitsev, A.M. Lozano, H. Auracher, O.A. Kabov, Microgravity Sci. Technol. 19, 71 (2007)

11. A. Orell, S.G. Bankoff, Int. J. Heat Mass Tran.14, 1835 (1971)

12. J.P. Burelbach, S.G. Bankoff, S.H. Davis, Phys. Fluid. A 2, 321 (1990)

13. D.V. Zaitsev, O.A. Kabov, Microgravity Sci. Technol 19, 174 (2007) 